\title{
Modelling of Eutectoid Transformation in Plain Carbon Steel
}

\author{
M. MUNIRAJULU, B. K. DHINDAW, A. BISWAS ${ }^{1)}$ and A. ROY ${ }^{2)}$
}

Department of Metallurgical Engineering, Indian Institute of Technology, Kharagpur-721302, India.

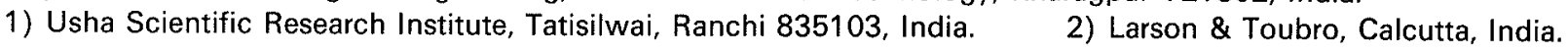

(Received on September 27, 1993; accepted in final form on January 21, 1994)

\begin{abstract}
A numerical model has been presented in this paper which simulates the austenite to pearlite phase transformation undergone by a $0.8 \%$ plain carbon steel. Both heat transfer and phase transformation were modelled and the model was verified by matching the complete cooling curve. The macro-microscopic model developed for the austenite-pearlite (eutectoid) reaction was in particular verified for its accuracy by matching eutectoid hold time. However in this work the nucleation rate was not modelled and the growth rate was modelled with a fixed number of nucleants. The results including the undercooling obtained were satisfactory in spite of these drawbacks.
\end{abstract}

KEY WORDS: heat transfer; eutectoid phase transformation; austenite; pearlite; nucleation and growth; Zener-Hillert model.

\section{Introduction}

Mathematical modelling has found wide spread applications in general area of material processing and in particular solidification processing, as a tool for optimization and control. ${ }^{1,2)}$ However solid state phase transformation controlled processes have not been much explored. ${ }^{3)}$ The models which are generally available in this field are mostly analytical and are thoroughly microscopic. The advantages of using macro-microscopic approach of modelling as used in the present work needs no emphasis as apart from their utility in process optimization, it also gives some insight into various mechanisms of phase transformation suggested in the literature. The system chosen here is the eutectoid transformation in the plain-carbon steel. The major constituent of this transformation is the formation of pearlite from austenite. Efforts have been made to model the cooling curve of $0.8 \% \mathrm{C}$ steel while being air cooled from the austenitizing temperature. The curve obtained through solution of the differential equations developed by numerical analysis was matched with that obtained by actual experimentation. The explicit scheme of the finite difference method was used while generating the numerical solutions.

The general governing equation for a transient one dimensional heat conduction in cylindrical coordinates used was

$$
\frac{\partial^{2} T}{\partial r^{2}}+\frac{1}{r} \frac{\partial T}{\partial r}=\frac{1}{\alpha} \frac{\partial T}{\partial t}
$$

The heat of the eutectoid reaction which is evolved during transformation of the austenite to pearlite constitutes a heat source and was incorporated in the above equation while modelling the thermal profile when the reaction is taking place. A pearlite growth rate equation based on Zener-Hillert model which assumes that the supersaturated parent phase is in local equilibrium with the product phase at the transformation front and that the volume diffusion of carbon in austenite is rate controlling was incorporated in the heat source term. ${ }^{4)}$ Compared to the earlier works, ${ }^{5,6)}$ the growth process in the present study was accounted by the atomic attachment kinetic model as is done in the liquid-solid phase transformation modelling. To gain insight into the kinetic aspects, the isothermal hold time for the experiments was matched with the simulated runs. This matching of the times was assumed to be the criteria for validation of the model.

\section{Numerical Model}

The following assumptions were made to simplify the system:

(1) There is a unidirectional heat flow radially outwards in the case of a long thin cylinder.

(2) At the specimen surrounding interface heat output is by radiation and convection.

When the system undergoes no phase transformations, then the heat flow can be described by the following equation in cylindrical coordinates

$$
\frac{\partial^{2} T}{\partial r^{2}}+\frac{1}{r} \frac{\partial T}{\partial r}=\frac{1}{\alpha} \frac{\partial T}{\partial t}
$$

When a phase transformation takes place the associated change in the enthalpy constitutes a heat source as in the case of austenite to pearlite transformation and the quantity of it evolved per unit time is dependent on the fraction of solid that is formed. The heat flow in this case is represented as: 


$$
\frac{\partial T}{\partial t}=\alpha\left(\frac{\partial^{2} T}{\partial r^{2}}+\frac{1}{r} \frac{\partial T}{\partial r}\right)+\frac{\dot{q}}{\rho \cdot c_{p}}
$$

where $\dot{q}$ is the heat input due to enthalpy change $\Delta H$ and is

$$
=-\frac{\partial f}{\partial t} \cdot \Delta H
$$

The eutectoid reaction has a finite growth rate and is nucleation and growth controlled phenomena. Since the system is a continuous cooling, hence simultaneously the specimen will undergo undercooling, phase transformation and release of heat of reaction.

To represent the above phenomena mathematically certain assumptions were made for simplification, they are:

(1) The eutectoid colonies were all spherical in shape and were distributed uniformly.

(2) Each colony grew essentially at the same rate.

(3) The average grain diameter is the mean free path of diffusion for the atoms and the number of nuclei formed is calculated from this data.

The equation representing this phenomena is as follows:

$$
\rho \cdot c_{p} \cdot \frac{\partial T}{\partial t}-\Delta H \cdot \frac{\partial f}{\partial t}=k \frac{\partial^{2} T}{\partial r^{2}}+\frac{k}{r} \frac{\partial T}{\partial r}
$$

Equation (2) is identical to Eq. (3) with some terms rearranged. The second term on the left of Eq. (3) is the heat source term due to eutectoid reaction.

With the assumption made, volume of a particular nucleus $V=(4 / 3) \pi x^{3}$ where $x$ is the instantaneous radius of the nodule

$$
\text { or } \quad \frac{d V}{d t}=4 \cdot \pi \cdot x^{2} \frac{d x}{d t}
$$

where $d x / d t=$ velocity of growing pearlite.

Now for volume diffusion controlled growth model ${ }^{4)}$

$$
\frac{d x}{d t}=\text { constant } \cdot D_{c}^{\gamma} \cdot\left(\frac{\Delta H \cdot \Delta T}{4 \cdot \sigma \cdot T_{e}}\right)^{2}
$$

Growth in the radius in time ' $d t$ ' is ' $d x$ '.

The fraction transformed can be expressed as

$$
\begin{aligned}
f & =N_{v} \cdot \frac{4 \pi}{3} \cdot x^{3} \\
\text { or, } \quad \frac{\partial f}{\partial t} & =4 \cdot \pi \cdot N_{v} \cdot x^{2} \cdot \frac{d x}{d t}
\end{aligned}
$$

We can calculate $f$ for every value of $x$, when $f$ becomes 1, the eutectoid transformation is over. Equation (3) can be rearranged and its finite differential approximation can be witten as:

$$
\begin{aligned}
T_{(i, j+1)}= & T_{(i, j)}+\frac{l \cdot \Delta H}{\rho c_{p}} \cdot 4 \cdot \pi \cdot N_{v} \cdot x^{2} \cdot \frac{d x}{d t} \\
& +\frac{\alpha \cdot l}{h^{2}}\left(T_{(i-1, j)}-2 T_{(i, j)}+T_{(i+1, j)}\right) \\
& +\frac{\alpha \cdot l}{r(i) \cdot h}\left(T_{(i+1, j)}-T_{(i, j)}\right)
\end{aligned}
$$

For evaluating the value of $d x / d t$ in Eq. (4), from the TTT diagram for a $0.8 \%$ plain carbon steel, time for completion of the reaction for various undercoolings $\Delta T$ were noted. In the present model (i.e. normalizing of steel) the transformation occurs with very small undercooling, thus variation of $d x / d t$ (growth rate) with temperature will be described by change in $\Delta T$ (undercooling). The terms $\Delta H$ and $\sigma$ in Eq. (4) are assumed to be relatively independent of temperature.

Equation (4) can be rewritten as

$$
\frac{d x}{d t}=Q \cdot\left(\frac{\Delta T}{T_{e}}\right)^{2}
$$

Determination of $d x / d t$ which is equal to $\Delta x / \Delta t$ for isothermal transformation will not be accurate near the eutectoid temperature $T_{e}$ as the slope of TTT curve is very small in this region. Hence the values of $T$ and $t$ were measured over a range of $200 \mathrm{~K}$ undercooling and variation of $Q$ with temperature was considered and a mean value of $Q$ at $1000 \mathrm{~K}$ was estimated to be $2.8 \times$ $10^{-6} \mathrm{~m} / \mathrm{s}$.

\subsection{The Boundary Conditions}

So far all the equations those were derived are applicable within the internal mesh only. The center and the surface are two boundaries.

In the outer most segment the heat transfer:

(1) Heat output (lost) is by radiation and convection.

(2) Heat input is by conduction.

(3) Heat given out due to eutectoid transformation is the internal heat source.

The following equation is used to generate the thermal history for the outer most volume segment:

$$
\begin{aligned}
T_{(1, j+1)}= & T_{1}-l\left[\operatorname{AR} 1\left\{E\left(T_{1}^{4}-T A^{4}\right)+\mathrm{h} 1\left(T_{1}-T A\right)\right\}\right. \\
& -\frac{k}{h}\left(T_{2}-T_{1}\right) \mathrm{AR} 2 \\
& \left.-N_{v} \cdot \Delta H \cdot 4 \pi \cdot x^{2} \cdot \frac{d x}{d t} \cdot 2 \pi R h L\right] /\left(2 \pi R h L c_{p} \rho\right)
\end{aligned}
$$

where, $\quad E=\varepsilon \times 5.67 \times 10^{-8} \mathrm{~W} / \mathrm{m}^{2} \mathrm{~K}^{4}$,

$$
\begin{aligned}
& \mathrm{h} 1=10^{-5} \mathrm{~W} / \mathrm{m}^{2} \mathrm{~K} \quad \text { (derived), } \\
& T_{1}=T_{(1, j)}, \quad \text { and } \\
& T_{2}=T_{(2, j)} .
\end{aligned}
$$

For, the center element, because of the symmetry of the body, we can conclude that there is no heat flux across the center. Therefore Eq. (3) can be used incorporating a virtual zeroth element which will have the temperature same as that of the first element (center element).

\section{Experimental}

A $0.82 \% \mathrm{C}$ eutectoid steel sample, $12 \mathrm{~mm}$ diameter and $100 \mathrm{~mm}$ length initially with spherodised carbide structure was taken. The sample was austenitized and normalized to get pearlitic structure.

The experiment was so designed as to adhere as far as possible to the assumption made while constructing the numerical model. A chromel-alumel thermocouple 
was placed in the center of the sample by drilling a hole. The sample was placed inside a furnace to austenitize it. The thermocouple was connected to the A/D converter, which digitized the analog data and fed to the IBM PC. The data acquisition was done with the help of a software called Unkelscope. After austenitizing the sample at a temperature of $1065 \mathrm{~K}$, it was pulled out of the furnace and allowed to cool in the air at ambient temperature of $303 \mathrm{~K}$. The thermal data was collected through the above data acquisition system. The pearlite nodule size was measured with the help of a microscope. The average size was found to be $2 \times 10^{-5} \mathrm{~m}$. This value was used for calculation of the number of nuclei/volume.

It is given by the formula

$$
N_{v}=\frac{3 \pi^{2}}{32(\bar{d})^{3}}
$$

where, $\bar{d}=$ average nodule size.

Values of the essential thermophysical parameters those used in modeling are one very important aspect on which the viability of the model depends. The thermophysical parameters for $0.8 \% \mathrm{C}$ steel were mostly derived from the reference. ${ }^{4,7)}$ Appropriate variations of the parameters were either taken from the tables or calculated using equations.

\section{Results and Discussion}

The experimental and simulated cooling curves for the eutectoid plain carbon steel samples are shown in Fig. 1. The eutectoid hold time for experimental cooling curve was measured to be $52 \mathrm{sec}$. By doing proper correction for emissivity value due to the presence of oxide scale on the sample surface $(=0.8$ in present case), the eutectoid hold time in the simulated mode is found to be nearly same as that for experimental cooling curve (approx. $52 \mathrm{sec}$ ).

On comparison of the modelled and the experimental

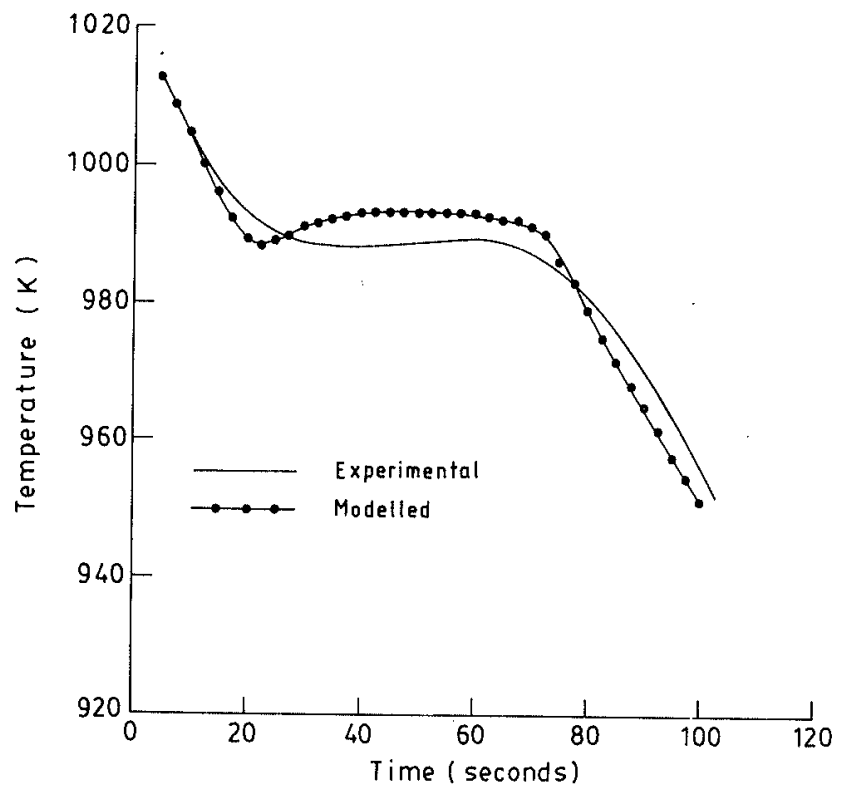

Fig. 1. Experimental and modelled cooling curves superimposed for normalizing of a $\mathrm{Fe} 0.8 \% \mathrm{C}$ steel (Munirajulu et al.). cooling curves, it is observed that general level of undercooling is the same for both of them, however, the modelled cooling curve show about $4 \mathrm{~K}$ higher recalascence temperature. This is perhaps due to the fact that in the modelled cooling curves the initial number of nuclei have been assumed to be the same as final seen in the transformed microstructure, where as for the experimental curve, the number of nuclei gradually increases to the final value. Therefore higher recalascence is seen in the modelled curve.

So, in general, from the above two matching, we can conclude that the growth rate equations used for developing the model and the heat transfer conditions assumed, describe the system more or less accurately.

Pearlite nodule size varies with the cooling rate. For our experimental conditions we measure the nodule size, and calculated the number of nuclei per unit volume. But if the cooling rate is changed then we cannot use this value of the nodule size, so for a generalized model where cooling rates can be changed as per our wish we have to represent $N_{v}$ as a function of cooling rate. This can be done by doing experiments at different cooling rates and measuring those particular $N_{v}$. Then we can do regression analysis to get an equation for $N_{v}$ in terms of cooling rate and undercooling which can be used in the present model.

\section{Conclusions}

An investigation has been presented which examine the processes those are involved while a cylindrical eutectoid plain carbon steel sample cools down in open atmosphere at ambient temperature from austenitizing temperature. Both the processes involved i.e. heat flow and phase transformation have been modelled simultaneously by numerical techniques and then compared with experimental data. Though the differential equations were changed to incorporate the additional heat source due to the eutectoid phase transformation, but the nucleation rate was not modelled and a fixed number of nucleants were assumed to be present. Though this latter assumption is not valid in real system still an undercooling and recalascence phenomena was observed and the predicted isothermal eutectoid hold time matched well with the experimental value. So the model worked out in the present work seems to describe the eutectoid transformation in plain carbon steels well in spite of the above drawback.

\section{Nomenclature}

$T: \quad$ temperature $(\mathrm{K})$

$t:$ time (sec)

$r$ : distance from the axis (i.e. radius) (m)

$\alpha:$ thermal diffusivity $\left(\mathrm{m}^{2} / \mathrm{sec}\right)$

$\rho:$ density $\left(\mathrm{kg} / \mathrm{m}^{3}\right)$

$c_{p}:$ specific heat $(\mathrm{J} / \mathrm{kg} \mathrm{K})$

$\Delta H:$ enthalpy change per unit volume between the decomposed phases from austenite $\left(\mathrm{J} / \mathrm{m}^{3}\right)$

$f:$ fraction transformed

$D_{c}^{\gamma}$ : diffusion coefficient of carbon in austenite $\left(\mathrm{m}^{2} / \mathrm{sec}\right)$

$T A:$ ambient temperature (K) 
AR1: area of the outer surface of the cylinder $\left(\mathrm{m}^{2}\right)$

AR2: surface area of the inner surface of the outermost volume segment $\left(\mathrm{m}^{2}\right)$

$N_{v}:$ number of nuclei in unit volume (number $/ \mathrm{m}^{3}$ )

$l:$ smallest time segment $(\mathrm{sec})$

$\varepsilon$ : emissivity

$k$ : thermal conductivity $(\mathrm{W} / \mathrm{m} \mathrm{K})$

h1: heat transfer coefficient for free convection $\left(\mathrm{W} / \mathrm{m}^{2} \mathrm{~K}\right)$

$h$ : thickness of each volume segment $=R / 10$ (m)

$L:$ length of the sample (m)

$R:$ radius of the sample $(\mathrm{m})$

$Q: \quad(\Delta H / 4 \sigma)^{2} \cdot$ constant $\cdot D_{c}^{\gamma}(\mathrm{m} / \mathrm{s})$

$\dot{q}$ : internal heat source $(d q / d t)\left(\mathrm{J} / \mathrm{m}^{3} \mathrm{sec}\right)$

$T_{(i, j)}:$ temperature $(\mathrm{K})$ of $i$-th element at $j$-th instant of time

$T_{(i, j+1)}$ : temperature (K) of the $i$-th volume element at $j+i$-th instant of time

$T_{e}:$ eutectoid transformation temperature (K)

$\lambda$ : interlamellar spacing $(\mathrm{m})$ $\sigma:$ interfacial energy $\left(\mathrm{J} / \mathrm{m}^{2}\right)$

Thermophysical parameters used

$$
\begin{aligned}
k & =33 \mathrm{~W} / \mathrm{m} \mathrm{K} \\
c_{p} & =716 \mathrm{~J} / \mathrm{kg} \mathrm{K} \\
\rho & =7657 \mathrm{~kg} / \mathrm{m}^{3} \\
\Delta H & =607 \mathrm{MJ} / \mathrm{m}^{3}
\end{aligned}
$$

\section{REFERENCES}

1) Metals Handbook, Vol. 15, 9th Ed., ed. by D. M. Stefanescu, ASM, Metals Park, Ohio, (1988), 883.

2) D. M. Stefanescu, G. Upadhya and D. Bandopadhyay: Metall. Trans., 21A (1990), 997

3) P. S. Das, A. Biswas and B. K. Dhindaw: Acta Metall., 40 (1992) 471 .

4) N. Ridley: Proc. Int. Conf. Phase Transformations in Ferrous Alloys, ed by A. R. Marder and J. I. Goldstein, TMS, Warrendale, (1984), 201.

5) Hildenwall and Ericsson: Hardenability Concepts with Applications to Steel, ed. by Doane and Kirkaldy, AIME, (1978), 579.

6) S. Taniguchi, T. Murakami, A. Watanabe and A. Kikuchi: Tetsu-to-Hagané, 74 (1988), 318.

7) E. I. Kazantsev: Industrial Furnaces, Mir Publishers, Moscow, (1977), 62. 